\title{
Processing, storability, physico-chemical properties and human health benefit of edible oil: A review
}

\author{
Ratnesh Kumar*, Suresh Chandra, Samsher, Vikrant Kumar, Kapil Kumar and Sunil \\ Department of Agricultural Engineering \\ SVPUAT, Meerut (UP) \\ *Email: rkindian563@gmail.com
}

\begin{abstract}
There are varieties of cooking oil and fat available today and the claims made by them are, at best, confusing. On one side are the traditional ghee, mustard oil, coconut oil, and gingelly oil. Then, there are the used for-decades vanaspati and groundnut oil, as well as the relatively newer kinds of vegetable oil ranging from cottonseed, sunflower, safflower, corn, canola, soybean, and palm to various blends. Lipids are considered one of the most elemental nutrients for humans. Vegetable oil is derived from seeds of plants. Among the oilseeds cultivated in India, from which edible oil is obtained, are groundnut, rapeseed, mustard, safflower, sunflower, soyabean, linseed. The other sources of vegetable oil are palm, cottonseed, coconut and rice bran. They contain essential fatty acids which play an important role in nutrition and also carriers of fat soluble vitamins. It is estimated that about $90 \%$ of vegetable oils are used for edible purposes, while the remaining part finds industrial applications. Edible oils processing poses challenges due to its high content of polyunsaturated fatty acids and bioactive compounds. Because the reproductive system in both men and women is constantly producing and dividing new cells, there is potential for mutation and problems when these cells are made of the wrong kind of fats and are oxidized. Because vegetable oils oxidize easily, they deplete the body of antioxidants since the body must use these to attempt to neutralize the oxidation.
\end{abstract}

Keywords: Edible Oil, Health Oil, Comparability, Nutrition, Physicochemical Properties.

Paper cited: Kumar, R., Chandra, S., Samsher; Kumar, V., Kumar, K. and Sunil (2018). Processing, storability, Physico-chemical properties and human health benefit of edible oil: A review. South Asian Journal of Food Technology and Environment, 4(2): 668-679.

\section{Introduction}

Vegetable oil is an important and widely used lipid source for our everyday (diet products). Its application is increasing day by day for food purposes and for the manufacturing of a number of toiletry products (Kumar et al., 2018). Edible oil, being obtained from vegetable sources, is primarily composed of fatty acids and used for cooking, medicinal and cosmetic purposes. It is estimated that about $90 \%$ of vegetable oils are used for edible purposes. Vegetable oils have wide application in foods where they are used in frying, cooking etc. Vegetable oils are produced from plant seeds, commonly used for frying, baking and other types of cooking. Edible oils and fats are biological mixtures.

Rapeseed (Brassica napus L.) is now the second most important source of vegetable oil in the world. Canola oil is also considered healthy for human nutrition due to its lowest content of saturated fatty acids among vegetable oils and moderate content of polyunsaturated fatty acids (Stamer et al., 1999). Quality is a comparative term essential to identify a germplasm with better nutritive value. Now days, consumers are not only concerned about what they eat but also how the consumed ingredients affect their health. A large variability in nutritional quality parameters exists not only between different oilseed crops, but also between Brassica species/genotypes. Although, oil content is the major quality parameter, seed meal protein content is also very important as it can be used to eliminate protein malnutrition in animals. Rapeseed-mustard oil quality is determined by the constituent fatty acids including palmitic, stearic, oleic, linoleic, linolenic, eicosenoic and erucic acids. Linoleic and linolenic acids are essential fatty acids not synthesized by our body. Erucic acid, although, anti-nutritional and should be $<2 \%$ 
in the edible oil, higher erucic acid is of considerable industrial importance.

Groundnut (Arachis hypogeal L.) is an important oilseed crop as it contains $44-56 \%$ oil and $22-30 \%$ protein on a dry seed basis (Reddy et al., 2003). Groundnut otherwise called peanut, monkey nut, gobber pea and arachide belongs to the family leguminosea (Gibbon and Pain, 1985; Abalu and Etuk, 1986). In addition, they are a good source of minerals (phosphorus, calcium, magnesium and potassium) and vitamins (E, $\mathrm{K}$ and $\mathrm{B}$ groups), (Hassan and Ahmed, 2012). Peanut also contain polyphenols, phytosterols, active polysaccharides, phospholipids, dietary fiber and other bioactive ingredients. Fatty acids are important diet for healthy living. They have several functions in the body including helping in transportation of oxygen in the bloodstream, aiding cell membrane development and function (necessary for strong organs and tissue), keeping the skin healthy, preventing early aging, and more importantly, preventing cholesterol build up in the arteries. The composition of fatty acids in peanut oil varies both in quality and in relative proportion (Onemli, 2012). Groundnut oil is excellent food oil, with good flavor and high quality with its low free fatty acid value. Vegetable oils generally primarily consist of triglycerides but several other compounds are also present. Some of these additional compounds such as diglyceride, tocopherols, sterols and sterols ester need not necessarily be removed during processing. Compounds such as phosphatide, free fatty acids, odiferous volatiles, colorant, waxes and metal compounds negatively affect taste, smell, appearance and storage stability of the refined oil and hence must be removed. Carefully separated, however, some of these additional compounds, particularly the phosphatides are valuable raw materials (Belcher, 2008).

Soybean is a major source of high quality protein and Oil, and soybean seed quality is often determined by seed protein, oil, fatty acid, and mineral content. Therefore, improving soybean seed quality is key to improving human and animal nutrition. The use of soybean products in the feed and food industry has increased steadily (Gandhi, 2006). The dominant position of soybeans and their products is primarily associated with their high nutritional quality especially with respect to protein and amino acids. While basic standards specifications for soybeans/soy meals have been established (NOPA, 1997), no official specifications exist for other soy products that are used now a days.

Sunflower (Helianthus annuus L.) is cultivated for its seeds' high oil content. Oil represents up to $80 \%$ of its economic value. The industrial processes for oil production consist of four successive stages: trituration, pressing, extraction of the residual oil using hexane a refining (Isobe et al., 1992; Rosenthal et al., 1996). The extraction yields are close to $100 \%$ with very good oil quality. Sunflower is the fourth biggest source of vegetable oil after soybean, palm and rapeseed. Major sunflower growing countries in the world are Russia, Ukraine, United States, France, Canada, Hungary, Romania, CIS, Argentina, Bulgaria Europe, Turkey, Serbia, South Africa, China and India (FAO, 2005). Sunflower seeds are very rich in protein and in essential fatty acids. These nutrients are essential for the good health of the nerves, brain and eyes and for the general health. More than half a sunflower seed is made up of the valuable and highly nutritive Sunflower oil.

The cultivated oil palm was first illustrated by Nicholas Jacquin in 1763, hence its name, Elaeis guineensis Jacq. There is fossil, historical, and linguistic evidence for an African origin of the oil palm (Hartley, 1988). In less than 100 years oil palm has moved from being a relatively minor subsistence crop in West and Central Africa to one of the world's major agricultural commodities. While oil palm in Africa has been cultivated for centuries by deliberate plantings and selective clearing (Zeven, 1972; Smith et al., 1992), it has recently expanded dramatically in Southeast Asia (Wicke et al., 2011), and increasingly in Africa and Latin America. The expansion is driven by producers responding to real and anticipated increase in consumer demand (Corley, 2009), much of which is from India and China. Oil palm provides much needed revenue to rapidly developing countries, and is an economic boon to thousands of people in tropical rural regions, although economic benefits are not distributed evenly (Rist et al., 2010; Obidzinski et al., 2012). As a major contributor to the economies of several developing countries, the expansion of oil palm cultivation is now a government priority throughout the humid tropics including some of the world's poorest countries. Oil palm expansion has mostly 
taken place in biodiversity-rich tropical rainforest areas (Carlson et al., 2012).

Rice bran oil is the oil is extracted from rice bran with high smoke point of $232^{\circ} \mathrm{C}\left(450^{\circ} \mathrm{F}\right)$ and its mild flavor, making it suitable for hightemperature cooking methods such as stir frying and deep frying. It is popular as cooking oil in several Asian countries, including Japan, India and China, Bangladesh. Rice bran oil is less expensive non-conventional oil and it improves the more stability of the blended oil due its nutrient composition. Rice bran is one of the most abundant biomass in the world. Its production amount is about 50-60 million tons per year which is normally used as animal food. It is a natural resource of minerals, proteins, carbohydrates, vitamins, and antioxidants. In addition, this biomass contains 10$26 \%$ oil which is used for different purposes. Rice bran oil has several unique nutritional properties; however, less than ten percent of this valuable oil is used for edible oil production. Rice Bran Oil (RBO) is miracle product obtained from the outer brown layer of rice. Current annual world rice bran oil production is estimated to be less than 8 lakh tons or about 1 per cent of all vegetable oils used for human consumption (Kusum et al., 2011). India is the second largest producer of crude rice bran oil in the world. India produces 120 million tons of paddy annually which contain 5-6 per cent of rice bran, leading to production of 6-7 million tons of rice bran oil. Rice bran contains 16 per cent oil, hence there is a potential for production of 1- 1.2 million tons of rice bran oil in the country but the actual production of rice bran oil is only 0.5-0.6 million tons (Usha and Premi, 2011).

Cottonseed oil, a by-product of cottonseed, is a valuable source of edible oil. The whole cottonseed contains $15-20 \%$ oil and about $30-38 \%$ of kernel, depending on the quality of seed and the species. Meanwhile, the free fatty acid and quality of oil depend on the weather prevailing during the time that cotton stands in the fields after coming to maturity. Cottonseed contains approximately 18$25 \%$ of oil and $20-25 \%$ high quality protein. The global annual production of cotton seed could potentially meet the total protein requirement of nearly half a billion people for a year @50 grams / day (Rathore, 2007) but presently cottonseed is not used in food preparations. Biodiesel production can be achieved using waste vegetable oils due to their low cost. They are collected from large food processing units and service facilities. They include several chemical reactions such as hydrolysis, polymerization and oxidation during food frying process, which leads to increased efficiency of fatty acids. In this regard's an effort has been made to produce the low-cost eco-friendly and high efficiency biodiesel by Cotton seed oil. The effect of temperature, catalysis loading reaction time and methanol oil ratio was also studied.

\section{Oil Extraction methods}

Ghani: The ghani consists of a large mortar and pestle, the mortar being fixed in the ground and the pestle being moved within the mortar by animal traction (donkey or mule) or (more commonly) a motor. Oilseeds are placed in the mortar and the pestle grinds the material to remove the oil. The oil runs out of a hole in the bottom of the mortar and the cake is scooped out by hand. This method is slow and requires two animals, replacing the tired one with another after about 3-4 hours of work. Motorized ghanis are faster than manual or animal types but are more expensive and their higher capital and operating costs will require a larger scale of production for profitability. The width of this gap, which can be varied using an adjustable pressure cone, controls the operating pressure of the press. The design of the press is such that it can achieve operating pressures in excess of those obtained in most manually operated cage presses and as high as those in small expellers. The ram press has a low seed throughput but has the advantage of continuous operation. The technique can also be used for copra, groundnuts and sesame (Kate el al., 2014).

Mechanical Oil Processing: The technique for oil extraction by mechanical presses is the most conventional one among the other methods. In this method, either a manual ram press or an engine driven screw press was used. The mechanical oil extraction technique was conducted using a mini 40 screw press at Centre for Plant and Water science (CPWS) in Central Queensland University (CQU). Properly dried and treated beauty leaf kernel samples were used to extract oil by this method. It was found to be very difficult to process kernel by using this screw press. Three samples of whole and three samples of grated kernels were used to perform the experiment. Seed kernel samples were ground using a blender machine. Operator was required constantly to attend and operate the machine. It has been observed that the rate of oil 
production was very slow, typically taking couple of hours to process just one sample. It could be noted that grated kernels provided higher oil yields than the whole kernels (Azad et al., 2012).

- Hydraulic press: The hydraulic press is considered of a series of horizontal corrugated iron plates. These plates are separated by 4 to 14 pre-moulded oil seed cakes. Pressing is completed in two stages. In first stage the oil samples are presented at approximately $5 \mathrm{MPa}$ for 15-20 minutes. After wards a pressure of $28 \mathrm{MPa}$ is applied for 5-10 minutes to complete the expression process. The output of the press varied depending on the size and seed being. In recent time at commercial level processing the hydraulic pressure has been replaced by screw type presses (Chandra et al., 2018).

- Screw Presses: Continuous screw pressing developed in early 1900 s, a practice that is still prevalent. The screw press consists of a flighted screw rotating within a slotted barrel. It is also often referred to as an "expeller" in the industry, which was actually a trademarked term used to denote a specific manufacturer's screw presses. The barrel is of fixed diameter and the root diameter of the screw increases from the feed end to discharge end. This design achieves increasing pressure by compensating for volume reduction due to product compaction, there by achieving oil removal through the slotted barrel while retaining the partially defatted solid mass within the barrel. In addition, throttle devices at the end of the barrel, called chokes, are available on some presses to enhance pressure build up. Continuous screw presses have been used in two ways in oilseed extraction for over the past century. The first is full-press operation, where the oilseed, after heat conditioning, is pressed one or more times through the same press or through several installed in series. In these cases, the screw press is the sole means of extraction and the objective is to achieve 5 - $6 \%$ residual oil content in the meal. In the second case, the screw press is used to remove part of the oil from oilseeds bearing high oil content ( $>30 \%$ oil) (Nanda, 2017).

Chemical Extraction: Solvent extraction is the process in which constituent is removed from a solid by means of a liquid solvent. It is also called leaching. The chemical extraction using n-hexane method results in the highest oil yield which makes it the most common method. Three samples of grated kernels were used to perform the oil extraction process. For chemical oil extraction, dried seed kernel samples were ground using a blender and coffee grinder to obtain a fine consistency to maximize particle surface area. The ground kernels were put into conical flasks in which n-hexane were added at a ratio of 2:1 (ml hexane: grams kernel). This mixture was given an initial stir to ensure that all kernels were wetted with hexane. Conical flask openings were covered with aluminium foil and placed on the orbital mixture shaker machine for shaking and the samples were left to run at least 20 to 24 hours. Then the hexane/oil mixtures were collected filtered and decant into aluminium foil containers for solvent evaporation and placed under the fume hood as shown in Fig. 4 for 20-24 hours. Jahirul et al., (2013) conducted the chemical oil extraction technique using n-hexane to extract oil from beauty leaf seeds (Calophyllum inophyllum). Hexane was again added to the conical flask of kernels, but at a ratio of $1: 1$ for the second extraction by applying the same procedure (Bhuiyaa el al., 2015).

Advanced methods: Modern commercial edible oil processing is based on the use of organic solvents, mainly a mixture of hexane isomers, nhexane being the major component. Hexane is highly flammable and explosive when mixed with air. Though n-hexane has been classified as a hazardous air pollutant, no new solvent has yet been approved or as a replacement.

Consequential environmental hazards of organic solvents and residues in oil oilseed-derived products have catalyzed the search for alternative solvents for edible oil processing. Ethanol, isopropyl alcohol, acetone, iso-hexane, and supercritical fluids (SCFs) have been studied as alternative solvents for the purpose (Nanda, 2017).

\section{Extruder in oilseed processing}

New awareness for food processing without the use of chemicals has stimulated development of approach to oilseed processing by using mechanical means based on extrusion technology as an alternative to the use of organic solvents. Extruders are mechanical devices in which a feed material is transported by a screw rotating within a closed 
barrel under varying conditions of heat, shear, and pressure then discharged through die openings in the optimal geometry for the desired product. These machines are used in processing food (e.g., snack foods and breakfast cereals), feed, pet food and industrial products (e.g., plastics).

Two types of extruders have found applications in the oilseed processing industry. The first type is the class of extruders called expanders. The general design of the expander consists of an unsegmented barrel housing a worm screw with interrupted flights. This design, derived from screw presses, was invented in 1963. Expanders are provided with needle valves at the flight interruptions to inject water or steam into the product stream (usually flakes). The expander converts flaked materials into porous collets that are much denser than flaked oilseeds and allow more material in the fixed-volume solvent extractor. This transformation increases the throughput capacity and efficiency of subsequent solvent extraction by enabling increased bed depth, better contact between solvent and oil, more complete solvent drainage and more cell disruption, thereby increasing plant capacity. Interrupted-flight expanders are used ahead of solvent extractors in many soybean-processing plants (Nanda, 2017).

\section{Effect of processing/treatments on oil quality}

The oil is subjected to extreme conditions during the process like oil extraction, refining, packaging, frying etc. These lead to quality deterioration of oils. The effect of some of the processes is described below.

Mixing or Homogenization: Mixing and homogenization are normally mild processes, but sometimes they can disrupt food structure, releasing enzymes that degrade fats. Two classes of enzymes are of particular importance. Lipases hydrolyze the complex lipids in food (mainly either triacylglycerols or phosphoglycerides), leading to release of free fatty acids (FFA). When free fatty acid concentrations reach a certain threshold, offflavors and unpleasant aromas may develop, but the FFA do not usually cause nutritional problems. The other type of enzyme is an oxygenase or peroxidase that catalyzes the oxidative deterioration of fatty acids once they have been released by lipases. Some of these enzymes (such as the lipoxygenase of plants) are involved in the formation of pleasant flavors characteristic of particular plant foods (e.g., the characteristic smell and taste of freshly cut cucumber), but oxidation of larger quantities of fatty acids may lead to off-flavors and toxic compounds (Jalgaonkar et al., 2017).

Heating: Fats heated under normal household conditions (at, say, $180^{\circ} \mathrm{C}$ ) generate 10 $20 \%$ of polymeric material, but at this level the functional properties of the oil are not noticeably impaired. The most important changes during heating involve reaction with oxygen from the air. Oxidation can take place when the fat is stored in the presence of oxygen at room or even refrigerator temperature but is greatly speeded up by heating and in the presence of trace metal catalysts (e.g., iron or copper). The major pathway is attack by oxygen at the double bonds of unsaturated fatty acids with the initial formation of peroxide. The more highly unsaturated the fatty acid, the greater is its susceptibility to oxidation. Free radicals produced during lipid peroxidation can reduce concentrations of essential fatty acid (EFA), vitamin $\mathrm{A}$, and vitamin $\mathrm{E}$. They may also cause damage to proteins, including enzymes, and DNA and may also generate carcinogens (Jalgaonkar et al., 2017).

Irradiation: Irradiation is also a process that may give rise to free radical formation and, therefore, lipid deterioration. This process is useful for controlling insect infestation of foods, reducing total microbial load, and reducing the numbers of specific pathogens in foods. It is not useful for all foods, and in many cases it can cause deterioration in palatability through poor flavor and texture. Vitamins E, K, and ascorbic acid are particularly susceptible to irradiation damage. Surprisingly, carotene has not been shown to be much affected.

Some highly unsaturated oils may suffer extensive damage due to a combination of free radical formation and reduction of antioxidant nutrients that would normally reduce the extent of free radical damage. Thus, these two types of damage may reinforce one another. When mixtures of unsaturated fatty acids and proteins have been irradiated prior to animal feeding, the quality of the protein was found to be reduced, probably due to protein damage by peroxidized lipids. In general, however, irradiation does very little direct nutritional damage (Jalgaonkar et al., 2017).

Interesterification: The process of interesterification, which involves treatment of a fat 
with a catalyst at an elevated temperature, leads to randomization of fatty acids on triacylglycerol molecules as distinct from their natural stereospecific distributions. Interesterification causes changes in the physical properties of the fats, such as crystal structure and melting point, and may influence their absorption and metabolism. Thus butterfat in which the fatty acids have been randomized by interesterification has minimal effect on plasma cholesterol, whereas natural butterfat tends to raise plasma cholesterol (Jalgaonkar et al., 2017).

Fractionation: The most abundant sources of medium-chain triacylglycerols (MCT) used in the preparation of human foods are coconut and palm, kernel oils, which contain $15 \%$ and $8 \%$ respectively of 8:0 + 10:0. The most abundant acid in these oils is lauric acid (12:0), which accounts for nearly $50 \%$ of the total fatty acids. Seed oils of Cuphea species also contain medium-chain fatty acids and could become another potential food source. Medium-chain fatty acids are rapidly absorbed in conditions in which the absorption of long-chain fatty acids may be impaired. Failure to digest lipids may occur because a disease has resulted in sufficient lipase or bile salt; malabsorption is generally due to damage to the mucosal surfaces of the small intestine. Absorption may also "back up" due to congenital failure to produce specific apoproteins that are obligatory components of plasma lipoproteins (Jalgaonkar et al., 2017).

In reduced cholesterol foods, most or part of the cholesterol has been removed by treatment with cholesterol-degrading enzymes or by differential extraction, for example by supercritical carbon dioxide extraction. This technology has been applied to eggs, fish, beef, and milk fat. There is little scientific justification for these products, since there is only a weak relationship between cholesterol in the diet and cholesterol in the blood. Their production is motivated by perceived marketing opportunities. It has been argued that in the long term, promotion of reduced cholesterol dairy products will do little for the credibility of the dairy industry (Jalgaonkar et al., 2017).

\section{Detection of quality of edible oil}

Free fatty acid (Acid value): When the temperature of storage condition increased, the carboxylic acid group may react to from esters and peroxides which degrade to aldehydes, ketones, and other secondary compounds. Hence, the number of available free hydrogen ions reduces (Chen et al., 2013). Higher fat acidity in vegetable oils used in present study might be due to the more content of polyunsaturated fatty acids thereby resulting in breakdown of triglycerides, increasing the free fatty acids which further increases the fat acidity (Preeti et al., 2007). Free fatty acids can stimulate oxidative deterioration of oils by enzymatic and or chemical oxidation to form off flavor components. Free fatty acid value is an indication of lipase activity (Ukhun, 1986). The free fatty acid was observed in soybean oil 0.18 and mustard oil 0.19 (Kumar et al., 2018). The Acid value for unblended palm oil was found to be $4.47 \%$ palmitic acid while those of sunflower oil and sesame oil were found to be $0.42 \%$ and $2.03 \%$ Oleic acid (Ngassapa et al., 2012).

Iodine value: The iodine value increase at elevated temperature could be attributed to destruction of double bonds in the oils upon heating. This could be due to the effect of high temperature causing destruction of $\pi$-bonds and hence decreasing the degree of unsaturation (Ngassapa et al., 2012). These low iodine values may have contributed to its greater oxidative storage stability. The oxidative and chemical changes in oils during storage are characterized by an increase in free fatty acid contents and a decrease in the total unsaturation of oils (Perkin, 1992). The iodine value was recorded in sunflower (2.20) and mustard oil (2.22) by Kumar et al., (2018).

Peroxide value: The peroxide value was also found to increase with the storage time, temperature and contact with air of the oil samples. Oils exposed to both atmospheric oxygen and light showed a much larger increase in peroxide value during storage. Increase of peroxide value with storage time has also been reported by Kamau and Nanua (2008). Peroxide value (PV) is used as a measure of the extent to which rancidity reactions have occurred during storage it could be used as an indication of the quality and stability of fats and oils (Ekwu and Nwagu, 2004). Kumar et al., (2018) were observed peroxide value in sunflower oil (0.16).

Refractive index: The high refractive index of oil also showed that the fatty acids in oil will contain a high number of carbon atoms. It is 
generalized that the refractive index of oils increases with increase the number of double bonds. With increase in temperature, the refractive index of oil decrease. The refractive indices can also be influenced by oxidative damage of oil (Pandurangan, et al., 2014).

Saponification value: Saponification value is an indication of the molecular weights of triglycerides in oil. It is inversely proportional to the average molecular weight or chain length of the fatty acids (Muhammad et al., 2011). The lower value of saponification value in the oil suggest that the mean molecular weight of fatty acids is lower than that of other vegetable oil or that the number of ester bonds is less when compared to that of other vegetable oil. The saponification value for the various oil samples decreased with increased temperature, this implies that soaps are formed easily with increase in temperature (Pandurangan et al., 2014). The saponification value in sunflower oil was found 192.6 (Sadoudi et al., 2014), and 186.13 (Ngassapa et al., 2012). Kavirajan et al., (2018) found RM value (220.54) for one year old ghee.

Reichert Meissl (RM) value: It is defined as the number of $\mathrm{mL}$ of $0.1 \mathrm{~N}$ alkali $(\mathrm{KOH})$ required neutralizing the volatile water soluble fatty acids in $5 \mathrm{~g}$ sample of oil/fat. The RM test determines the amount of bytyric and caproic acids which are readily soluble in water and the caprylic and capric acids which are slightly soluble. The RM value is particularly valuable in detecting adulteration in butter.

\section{Dietary requirement of fat for Indian}

Consumer obtained dietary fats from two major sources viz. the invisible fat, which is present in plant and animal foods; and the visible fat (fats and oils). Fats are the medium for cooking, serve as a vehicle for fat-soluble vitamins and carotenes and important for their absorption, important for satiety, and also a source of essential polyunsaturated fatty acids. But it is important to have good quality fat in adequate quantity having proper proportions of essential fatty acids/ polyunsaturated fatty acids. The type and quantity of fat in the daily diet influence the level of cholesterol and triglycerides in the blood.

The minimal intakes of visible fat in Indian adults range between 20-40 g/day, depending upon the physical activity, percent energy from fat and also considering unfavourable effects of low fat- high carbohydrate diets on health, $30 \mathrm{~g}$ visible fat by pregnant and lactating and 25-30 and 35-50 $\mathrm{g} /$ day, respectively of visible fat for children and adolescents. The maximum amount of total fat that can be included in the diet should not exceed 30\% of energy i.e. about $60 \mathrm{~g}$ visible fat/ day. Diets must include adequate amounts of good quality fat and oils particularly in the case of young children to provide concentrated source of energy, required for their growth and development and active and healthy life while adults need to be cautious and require to restrict saturated fat (butter, ghee and hydrogenated fats) and cholesterol in their diet (red meat, eggs, organ meat) to avoid the obesity, diabetes, cardiovascular disease and cancer etc (Mridula, 2017).

\section{Effect of dietary fat on food intake}

Studies had shown that high dietary fat induce greater food intake and thus weight gain than diets rich in carbohydrates. A number of factors such as energy density of meal, satiety characteristics and post-absorptive factors can contribute to different response to high-fat diets than high carbohydrates diet. Golay and Bobbioni (1997) indicated that the satiating effects after dietary intake with a higher fat: carbohydrate ratio is less than for meal having a lower ratio. They further indicated that dietary density of fat has a poor influence on satiety and that periodic exposure to a high-fat meal, mainly during intense hunger, may lead to over energy consumption as fat in obese patients. High-fat diets promote passive overconsumption, depends largely on the high energy density of high fatty foods and this overconsumption due to overeating has been attributed to as passive over-consumption (Stubbs et al., 1995). Blundell and Stubbs (1999) indicated that short-term studies on appetite of subjects and total energy intake clearly showed that fat is less satiating than carbohydrate and protein, and that high fat diets are more likely to induce passive over-consumption and thus weight gain than less fatty diets with higher protein and carbohydrate contents.

\section{Dietary fat and fat balance}

Golay and Bobbioni (1997) reported that energy balance is correlated with fat balance in lean controls and indicated no correlation with either carbohydrate or protein balances; and also reported that carbohydrate and protein reserves in the body 
is regulated by adjusting oxidation to intake, while dietary fat is almost exclusively used or stored in response to day-to-day variations in the energy balance. This study indicated the positive relationship between fat intake and lipid oxidation seen in lean controls appears not to be present in obese patients. Golay and Bobbioni (1997) reported that on high-fat diets, post-obese women failed to increase the ratio of fat to carbohydrate oxidation appropriately and dietary fat results in preferential fat storage in post-obese women, impaired suppression of carbohydrate and reduction of $24 \mathrm{~h}$ energy expenditure.

\section{Dietary fat and diseases}

Intake of fat is associated with occurrence of diseases particularly hypertension, heart diseases, diabetes mellitus. Cancers (colon, breast, prostate, and ovary cancer) has been debated for many years. Epidemiological studies showed that a high-fat diet promotes the obesity and has a direct relationship between the proportion of dietary fat intake and the degree of obesity. Studies carried out during the past 30 years have indicated the correlation of higher dietary fat intake with higher mortality due to various diseases. Consumption of specific saturated fatty acids raise blood cholesterol levels and, thereby increase the risk of atherosclerosis; higher fat intake is a major cause of obesity, hypertension, diabetes, gallbladder disease and may also increased the risk of breast cancer directly through increased blood estrogen levels and/or secondarily through increased obesity (Kuller, 1997). A number studies have indicated positive correlation between the proportion of total dietary energy intake from fat and body fatness, and inverse associations between carbohydrate intake and body fatness (Astrup et al., 1997; Bray and Popkin, 1998).

Excess bodyweight in overweight (defined as a body-mass index (BMI) of 25 to $29.9 \mathrm{~kg} / \mathrm{m}^{2}$ ) as well as in obese (BMI $30 \mathrm{~kg} / \mathrm{m}^{2}$ or grater) people, is becoming an impotent risk factor for some common cancers (IARC, 2002; WCRF, 2007). In a study carried out by Laura et al., (2002) conjugated linoleic acid (CLA) intake showed a weak but positive correlation with breast cancer incidence but statistically significant positive correlation with total trans fatty acids and (borderline) with saturated fatty acids. Laura et al., (2002) also observed that anti-carcinogenic property of CLA in animal and tissue culture models could not be confirmed in this epidemiologic study in humans. Andrew et al., (2008) indicated that in men, a 5 $\mathrm{kg} / \mathrm{m}^{2}$, increase in BMI was strongly associated with oesophageal adenocarcinoma and with thyroid, colon, and renal cancers. In case of women subjects, this study further reported a strong association between a $5 \mathrm{~kg} / \mathrm{m}^{2}$ increase in BMI, gallbladder, oesophageal adenocarcinoma, and renal cancers.

$\mathrm{Hu}$ et al., (2001) reported that the type of fat, but not total amount of fat, predicts serum cholesterol levels as shown in various metabolic studies. They further reported that controlled clinical trials as well as eidemiologic studies also indicated that replacement of saturated fat with unsaturated fat is more effective in lowering risk of CHD than simply reduction in the amount of daily fat consumption. Hu et al., (2001) further indicated that the prospective cohort studies and secondary prevention trials provided strong evidences that an increasing intake of omega-3 fatty acids (fish or plant sources significantly lowers the risk of cardiovascular diseases thus mortality by these diseases. Mario et al., (2013) in indicated that the observational evidence not support hypothesis that dairy fat or high-fat daily foods contribute to obesity or cardio-metabolic risk, and indicated that consuming high-fat dairy within typical dietary within typical patterns is inversely associated with the risk of obesity. Dietary fat particularly the fatty acids present in them influence glucose metabolism by altering cell membrane function, enzyme activity, insulin signaling, and gene expression (Riserus et al., 2008) reported that among polyunsaturated fats, linoleic acid improves insulin sensitivity whereas long-chain omega-3 fatty acids not appear to improve insulin sensitivity or glucose metabolism. Fat is an important dietary constituent must be included in the daily diet in adequate amount to fulfill the dietary requirement for growth and development of the body. However care should be taken to avoid the excessive intake of the total fat in general and saturated fat in particular to avoid the onset of obesity and other associated lifestyle related diseases.

\section{Storability of edible oil}

The type of oil will determine the degree of unsaturation or polyunsaturation and the normal level of natural antioxidants, and these factors 
should be borne in mind when deciding on the requirements for storage. Most other factors affecting degradation are more or less controllable:

- Minimize contact with or absorption of air.

- Avoid excessive moisture.

- Avoid contact with and minimize content of pro-oxidants.

- Keep oils in the dark.

- Keep time and temperature to a minimum.

- Avoid unnecessary agitation.

However, the precautions taken must also be economically justifiable, and they are usually related to the commercial risk involved in not taking them. A manufacturer must choose what precautions best serve his particular circumstances in relation to a type of oil or fat and the length of time it is to be held as well as development of FFA and oxidation of triglycerides changes in color may have to be consider. The factor which affect the oil during storage, are as described below.

Air Contact: A fat combined with as little as $0.016 \%$ of its own weight of oxygen could be sufficient to develop a peroxide value of $20 \mathrm{meq}$ $\mathrm{O}_{2} / \mathrm{kg}$. Those refined oils which are the most sensitive to the development of off-flavours by oxidation need to be stored under high quality nitrogen, whereas less sensitive oils-in general those with little linoleates or more unsaturated fatty acids-can be protected by normal good grade commercial nitrogen (Jalgaonkar et al., 2017).

Moisture: Hydrolysis of neutral oil is an important source of loss in handling. The solubility of water in neutral oils increases with rise in temperature and shortening of the chain lengths of the fatty acids combined in the fat. Solubility of water in fatty acids is greater than in the neutral fats of the corresponding fatty acid triglycerides. The oil should contain less than $0.1 \%$ water (Jalgaonkar et al., 2017).

Light: In the presence of light, photooxidation of oils takes place. As far as bulk handling of oil is concerned this largely takes place in the dark, so light assumes practical importance mainly in the field of packaging of finished products where the aim is to exclude it. Long-term storage trials are usually conducted in the dark as such a condition would be feasible in commercial practice (Jalgaonkar et al., 2017).

Temperature: If fat or oil is to be held undisturbed for a week or longer it probably is best to shut off all heating. Oil standing at ambient temperature may deposit some of its higher melting components implies that the stock should be mixed when reheated. The minimum and maximum temperature for short term storage should be 25 and $45^{\circ} \mathrm{C}$ for most of the oils (Jalgaonkar et al., 2017).

Catalysts: Enzymes is equivalent to contamination by any material, which promote oxidation or hydrolysis of the oil or its minor nonfat components. Often these effects would be loosely ascribed to the presence of dirt. However, specific contaminants such as copper, iron and lipases are recognized as particularly potent (Jalgaonkar et al., 2017).

\section{Conclusion}

Energy balance is an important factor to maintain healthy body weight. Lipids are considered one of the most elemental nutrients for humans. The oilseed processing industry primarily suffers from low utilization of installed capacity (30 to $38 \%$ ). Most of the oil mills and solvent extraction units are out-dated and in need of renovation / modernization, resulting in low oil recoveries and high unit costs. There is also lack of integration between our expelling and solvent extraction industries. Vegetable oils makes an important contribution to the diet of people, serving as a good source of lipid and fatty acids for human nutrition including the repair of worn out tissues, new cells formation as well as a useful source of energy. Edible fats and oils are similar in molecular structure; however, fats are solid at room temperature, while, oils are liquid. Fats and oils are essential nutrients, comprising about $40 \%$ of the calories in the diet of the average person. Edible vegetable oils are used as salad or cooking oils, or may be solidified (by a process called hydrogenation) to make margarine and shortening. Our dietary intake comprises three macronutrients (protein, carbohydrate and lipid) and a large but unknown number of micronutrients (vitamins, minerals, antioxidants, etc.). Good health rests, in part, on an adequate and balanced supply of these components. Most vegetable oils are obtained from beans or seeds, which generally furnish two valuable commodities - an oil and a protein-rich meal. Seed extraction is achieved by pressing and/or by solvent extraction. 


\section{References}

1. Abalu, G.O. and Etuk, E.G. (1986). Traditional versus improved groundnut production practices. Some further evidence from Northern Nigeria. Experimental Agriculture, 22: 33-38.

2. Andrew, G.R., Margaret, T., Matthias, E., Richard, F.H. and Marcel, Z. (2008). Bodymass index and incidence of cancer: a systematic review and meta-analysis of prospective observational studies. The Lancet, 371:569-78. DOI: $\quad$ 10.1016/S01406736(08)60269-X.

3. Astrup, A., Toubro, S., Raben, A. and Skov, A.R. (1997). The role of low fats diets and fat substitutes in body weight management: what have we learned from clinical studies? Journal of American Dietetic Association, 97(Suppl): $82 \mathrm{~S}-87 \mathrm{~S}$.

4. Azad, A.K., Uddim, S.M.A. and Alam, M.M. (2012). A Comprehensive Study of Di Diesel Engine Performance With vegetable Oil: An Alternative Bio-Fuel Source of Energy. International Journal of Automotive and Mechanical Engineering, 5: 576-586.

5. Belcher, W.M. (2008). Method for refining vegetable oils and byproduct. American oil Chemist Society. pp 110-115.

6. Bhuiyaa, M.M.K., Rasula, M.G., Khana, M.M.K., Ashwath, N., Azada, A.K. and Mofijura, M. (2015). Optimization of Oil Extraction Process from Australian Native Beauty Leaf Seed (Calophyllum inophyllum). Energy Procedia, 75:56-61.

7. Blundell, J.E., and Stubbs, R.J. (1999). High and low carbohydrate and fat intakes: limits imposed by appetite and palatability and their implications for energy balance. European Journal of Clinical Nutrition; 53(Suppl 1): S $148-165$.

8. Bray, G.A. and Popkin, B.M. (1998). Dietary fat intake does affect obesity. American Journal of Clinical Nutrition, 68: 1157 - 1173.

9. Carlson, K.M., Curran, L.M., Ratnasari, D., Pittman, A.M., Soares, B.S., Asner, G.P., Trigg, S.N., Gaveau, D.A., Lawrence, D. and Rodrigues, H.O. (2012). Committed carbon emissions, deforestation, and community land conversion from oil palm plantation expansion in West Kalimantan, Indonesia. Proceedings of the National Academy of Sciences of the United States of America, 109: 7559-7564.

10. Chandra, S., Kumari, D., Samsher, Kumar, V. (2018). Crop Process Engineering. The Jain Brothers, New Delhi.

11. Chen, W.A., Chiu, C.P., Cheng, W.C., Hsu, C.K. and Kuo, M.I. (2013). Total Polar Compounds and Acid Values of Repeatedly Used Frying Oils Measured by Standard and Rapid Methods. Journal of Food and Drug Analysis, 21(1): 58-65.

12. Corley, R.H.V. (2009). How much palm oil do we need? Environmental Science and Policy, 12: 134-139.

13. Ekwu, F.C. and Nwagu, A. (2004). Effect of processing on the quality of cashew nut oils. Journal of Science and Agriculture, Food Technology and Environment, 4: 105-110.

14. FAO, (2005). UN Food and Agriculture Organization "Major food and agricultural commodities and producers". FAO. http://www.fao.org/es/ess/top/commodity.htm 1?item/.

15. Gandhi, A.P. (2006). Soybean-the greater bean. World Grain (USA), February, p 59-62.

16. Gibbon, D. and Pain, A. (1985). Crops of the drier region of the tropics. Longman group ltd UK. P 146

17. Gilbert, D. (2013). Oil Palm and Palm Oil Industry in Ghana: A Brief History. International Research Journal of Plant Science, 4(6):158-167.

18. Golay, A. and Bobbioni, E. (1997). The role of dietary fat in obesity. International Journal of Obesity and Related Metabolic Disorders, 21 (Suppl 3): S2-11.

19. Hartley, C.W.S. (1988). The Oil Palm (Elaeis guineensis Jacq). Longman Scientific and Technical Publication. (Third Edition-Tropical Agriculture Series, pp. 694-703). John Wiley and Sons, NY.

20. Hassan, F. and Ahmed, M. (2012). Oil and Fatty Acid Composition of Peanut Cultivars Grown in Pakistan. Pakistan Journal of Botany, 44(2): 627-630.

21. $\mathrm{Hu}$, F.B., Manson, J.E. and Willett, W.C. (2001). Types of dietary fat and risk of coronary heart disease: a critical review. Journal of the American College of Nutrition, 20(1): 5-19. 
22. IARC, (2002). Weight control and physical activity. eds. Vainio, H, Bianchini, F. Lyon, France: International Agency for Research in Cancer Press.

23. Isobe, S., Zuber, F., Uemura, K. and Noguchi, A. (1992). A new twin-screw press design for oil extraction of dehulled sunflower seed. Journal of the American Oil Chemists' Society, 69: 884-889.

24. Jahirul, M.I., Brown, J.R., Senadeera, W., Ashwath, N., Laing, C., Leski-Taylor, J. and Rasul, M.G. (2013). Optimisation of Bio-Oil Extraction Process from Beauty Leaf (Calophyllum Inophyllum) Oil Seed as a Second Generation Biodiesel Source. Procedia Engineering, 56: 619-624.

25. Jalgaonkar, K., Sharma, K., Ratnakar, B.B. and Vishwakarma, R.K. (2017). Extraction, Refining and storage of Edible Oils: Methods and Future Expecctations. Compendium of ICAR-Summer School (Aug 1-21, 2017) on Advanced strategic processing techniques for oilseeds to combat protein-energy malnutrition and augment farmers income. (Ed: Yadav, D.N., Nanda, S.K. and Solanki, C.) ICARCIPHET, Ludhiana. pp- 44-56.

26. Kamau, J.M. and Nanua, J.N. (2008). Storage stability of ram press extracted semi-refined sunflower oil. Agriculture Tropical and Subtropical, 41(3): 106-109.

27. Kate, A.E., Lohani, U.C., Pandey, J.P., Shahi, N.C. and Sarkar, A. (2014). Traditional and mechanical method of the oil extraction from wild apricot kernel: a comparative study. Research Journal of Chemical and Environmental Sciences, 2(2):54-60.

28. Kavirajan, A., Shetty, S.K. and Savitha, H.P. (2017). Physico-chemical analysis of purana ghrita (one year old ghee). South Asian Journal of Food Technology and Environment, 3(2): 568-575.

29. Kuller, L.H. (1997). Dietary fat and chronic diseases: epidemiologic overview. Journal of the American Dietetic Association, 97(7 Suppl): S9-15.

30. Kumar, R., Chandra, S., Samsher; Kumar, K., Kumar, T. and Kumar, V. (2018). Analysis of the physical and chemical characteristics of edible vegetable blended oil. International Journal of Chemical Studies, 6(6): 10-15.
31. Kusum, R., Bommayya, H., Fayaz, P.P. and Ramachandran, H.D. (2011). Palm oil and rice bran oil: Current status and future prospects. International Journal of Plant Physiology and Biochemistry, 3: 125-132.

32. Laura, E.V., Brants, H.A.M., Alwine, F.M.K., Gerrit, J.H., Piet, A.V.D.B. and Goldbohm, R.A. (2002)). Intake of conjugated linoleic acid, fat, and other fatty acids in relation to postmenopausal breast cancer: the Netherlands Cohort Study on Diet and Cancer 1-3. American Journal of Clinical Nutrition, 76: 873-82.

33. Mario, K., Ton, B. and Stephan, G. (2013). The relationship between high-fat dairy consumption and obesity, cardiovascular, and metabolic disease. European. Journal of Nutrition, 52(1): 1-24.

34. Mridula, D. (2017). Role of oils and fats in human health and nutrition. Compendium of ICAR-Summer School (Aug 1-21, 2017) on Advanced strategic processing techniques for oilseeds to combat protein-energy malnutrition and augment farmers income. (Ed: Yadav, D.N., Nanda, S.K. and Solanki, C.) ICARCIPHET, Ludhiana. pp- 26-19.

35. Muhammad, N., Bamishaiye, E., Bamishaiye, O., Usman, L., Salawu, M., Nafiu, M. and Oloyede, O. (2011). Physicochemical properties and fatty acid composition of Cyperus esculentus (Tiger Nut) Tuber Oil. Bioresearch Bulletin, 5:51-54.

36. Nanda, S.K. (2017). Edible oilseed processing in India. Compendium of ICAR-Summer School (Aug 1-21, 2017) on Advanced strategic processing techniques for oilseeds to combat protein-energy malnutrition and augment farmers income. (Ed: Yadav, D.N., Nanda, S.K. and Solanki, C.) ICAR-CIPHET, Ludhiana. pp- 14-19.

37. Ngassapa, F.N., Nyandoro, S.S. and Mwaisaka, T.R. (2012). Effects of temperature on the physicochemical properties of traditionally processed vegetable oils and their blends. Tanzania Journal of Science, 38(3): 166-176.

38. NOPA. (1997-1999). Nation Oilseeds Processors Association, Year Book and Trading Rules, Washington, DC.

39. Obidzinski, K., Andriani, R., Komarudin, H. and Andrianto, A. (2012). Environmental and 
social impacts of oil palm plantations and their implications for biofuel production in Indonesia. Ecology and Society, 17.

40. Onemli, F. (2012). Impact of Climate Change on Oil Fatty Acid Composition of Peanut: In Three Market Classes. Chilean Journal of Agricultural Sciences, 72 (4):483-488.

41. Pandurangan, M.K., Murugesan, S. and Gajivaradhan, P. (2014). Physico-chemical properties of groundnut oil and their blends with other vegetable oils. Journal of Chemical and Pharmaceutical Research, 6(8): 60-66.

42. Perkin, E.G. (1992). Effect of lipid oxidation on oil and food quality in deep frying. In: Angels, A.J.S. (Ed.), Lipid Oxidation in Food, Chapter 18, ACS Symposium Series no. 500 ACS, American Chemical Society, Washington DC, pp. 310-321.

43. Preeti; Khetarpaul, N., Jood, S. and Goyal, R. (2007). Fatty acid composition and physicochemical characteristics of cooking oils and their blends. Journal of Dairying, Foods \& Home Science, 26 (3/4): 202-208.

44. Rathore, K.S. (2007). Reducing Gossypol in cottonseed may improve human nutrition, Deptt. of Social and Crop Science, Texas A and M University College Station TX.

45. Reddy, T.Y., Reddy, V.R. and Anbumozhi, V. (2003). Physiological responses of groundnut (Arachis hypogeal L.) to drought stress and its amelioration: A critical review. Plant Growth Regulation, 41: 75-88.

46. Riserus, U.I., Willett, W.C. and Hu, F.B. (2008). Dietary fats and prevention of type 2 diabetes. Progress in Lipid Research, 48(1): 44-51.

47. Rist, L., Feintrenie, L. and Levang, P. (2010). The livelihood impacts of oil palm: smallholders in Indonesia. Biodiversity and Conservation 19: 1009-1024.

48. Rosenthal, A., Pyle, D.L. and Niranjan, K. (1996). Aqueous and enzymatic processes for edible oil extraction. Enzyme and Microbial Technology, 19: 402-420.

49. Sadoudi, R., Ammouche, A. and Ali, A.D. (2014). Thermal oxidative alteration of sunflower oil. African Journal of Food Science, 8(3):116-121.

50. Smith, N.J.H., Williams, J.T., Plucknett, D. and Talbot, J.P. (1992). Tropical Forests and their Crops. Cornell University Press, Ithaca.
51. Stamer, D.E., Hamama, A.A. and Bhardwaj, L. (1999). Canola oil yield and quality as affected by production practices in Virginia, In: Janick J., (ed.) Perspectives on new crops and new uses, ASHS Press, Alexandria, VA. pp. 254-256.

52. Stubbs, R,J., Harbron, C.G., Murgatroyd, P.R. and Prentice, A.M. (1995). Covert manipulation of dietary fat and energy density: effect on substrate flux and food intake in men eating ad libitum. American Journal of Clinical Nutrition; 62: 316 - 329.

53. Ukhun, M.E. (1986). Effect of storage and processing on the nutritional value of certain nigerian foods. Experienta, 42:948-950.

54. Usha, P.T. and Premi, B.R. (2011). Rice bran oil - Natures gift to mankind. www.Nabard.com, 7: 1-2.

55. WCRF, (2007). World Cancer Research Fund. Food, Nutrition, Physical Activity, and the Prevention of Cancer: a Global Perspective. 2nd edn. Washington, USA: American Institute for Cancer Research.

56. Wicke, B., Sikkema, R., Dornburg, V. and Faaij, A. (2011). Exploring land use changes and the role of palm oil production in Indonesia and Malaysia. Land Use Policy, 28: 193-206.

57. Zeven, A.C. (1972). Partial and complete domestication of oil palm (Elaeis guineensis). Economic Botany, 26: 274-279.

\begin{tabular}{|ll|}
\hline Received & : Sept., 2018 \\
Revised & : Oct., 2018 \\
Published & : Dec., 2018 \\
\hline
\end{tabular}

